\title{
Determinação racional da vontade humana e educação natural em Rousseau*
}

\author{
Cláudio Almir Dalbosco \\ Universidade de Passo Fundo
}

Correspondência:

Cláudio Almir Dalbosco

Rua Independência, 1006 apto 81

99010-040 - Passo Fundo - RS

e-mail: cadalbosco@upf.br

"Trabalho vinculado ao projeto de pesquisa Iluminismo e Pedagogia, pertencente à linha de pesquisa Fundamentos da Educação do PPG em Educação e ao Núcleo de Pesquisa em Filosofia e Educação (Nupefe) da Universidade de Passo Fundo (UPF/RS). Agradeço ao Serviço Alemão de Intercâmbio Acadêmico (DAAD-Alemanha), à Fundação de Amparo à Pesquisa do Estado do Rio Grande do Sul (FAPERGS/Brasil), à Universidade de Kassel (UnikasselAlemanha) e à Universidade de Passo Fundo (RS/Brasil) pelo apoio financeiro de viagens e estadias na Alemanha e pelo financiamento de horas de pes quisa sem os quais este trabalho certamente não teria sido possível.

\section{Resumo}

0 presente artigo procura mostrar, por meio de um trabalho analítico-reconstrutivo, que na base do 'argumento secular' de Rousseau sobre a origem da maldade humana, desenvolvido no livro IV de Émile, está uma teoria da determinação racional da vontade que oscila entre os conceitos de consciência e razão. Pela expressão 'argumento secular', entende-se o fato de Rousseau ver a origem do mal não mais em uma força estranha nem mais no indivíduo isolado, mas sim na própria sociedade. 0 artigo pretende esclarecer também que, apesar dessa oscilação, tal teoria torna-se decisiva ao esboço de um projeto de educação natural oferecido pelo autor ao seu aluno imaginário no Émile. Uma vez que seu caráter é constituído pela trama de relações sociais, não há outra alternativa a Emílio senão a de buscar educar-se no convívio social, mesmo correndo o risco permanente de ser corrompido pela sociedade. Como o esboço da teoria da determinação racional da vontade humana está em estreita conexão com o esboço das teorias social e antropológica também oferecido por Rousseau no Émile, ele também deve arrolar argumentos para o confronto, por meio de um trabalho educativo da tendência egoísta do amour-propre, com o processo de estranhamento oriundo da sociabilidade humana, visando a recuperação do sentimento do amour de soi-même no convívio social.

\section{Palavras-chave}

Razão - Consciência - Vontade - Educação natural. 


\section{Rational determination of human will and natural education in Rousseau*}

Cláudio Almir Dalbosco

Universidade de Passo Fundo

Contact:

Cláudio Almir Dalbosco

Rua Independência, 1006 apto 81 99010-040 - Passo Fundo - RS

e-mail: cadalbosco@upf.br
"This work is linked to the research project Iluminismo e Pedagogia (Enlightenment and Pedagogy), which belongs to the line of research on Foundations of Education of the Graduate Program in Education, and to the Research Center on Philosophy and Education (Nupefe) of the University of Passo Fundo (UPF/RS). I am indebted to the German Service of Academic Exchange (DAAD-Germany), to the Research Foundation of the State of Rio Grande do Sul (FAPERGS/Brazil), to the University of Kassel (UnikasselGermany) and to the University of Passo Fundo (RS/Brazil) for the financial support with travels expenses and stays in Germany, and by the sponsoring of hours of research, without which this work would certainly not have been possible.

\begin{abstract}
This article seeks to show, with the help of an analyticalreconstructive work, that at the basis of Rousseau's "secular argument" about the origin of human evil, developed in book IV of the Emile, lies a theory of the rational determination of the will that oscillates between the concepts of conscience and reason. By the expression "secular argument" is understood here the fact that Rousseau no longer sees the origin of evil in a strange force, or in the singular individual, but in society itself. The present text attempts to clarify also that, despite this vacillation, such theory becomes decisive in the outline of a project of natural education offered by that author to his imaginary pupil in the Emile. Since his character is constituted in the intertwining of social relations, no alternative is left to Emile but to try to educate himself in the social exchange, notwithstanding the permanent risk of being corrupted by society. Because the outline of the theory of the rational determination of human will is closely associated with the drafts of social and anthropological theories also put forward by Rousseau in the Emile, he must also enlist arguments for the confrontation, through a work of education of the selfish tendency of the amour-propre, with the realization of otherness that comes from the human sociability, aiming at recovering the feeling of amour de soi-même in the social exchange.
\end{abstract}

\section{Keywords}

Reason - Conscience - Will - Natural Education. 
Taylor (1996) dedica um capítulo de seu extenso livro, Fontes do si mesmo: o nascimento da identidade moderna, para tratar de Rousseau e Kant, atribuindo-lhe o sugestivo título 'Natureza como fonte'. Considera Rousseau como um dos autores modernos que mais influenciou os contemporâneos e esboça uma interpretação relevante de seu pensamento ao conectar entre si os conceitos de natureza e consciência, derivando deles o recurso à 'voz interna' como busca incessante do eu para identificar-se consigo mesmo. A analogia constante entre natureza e voz interna deve-se ao fato, primeiramente, de que Rousseau, além de ter sido escritor, também fora músico. Com esse recurso, ele poderia ser considerado, em certo sentido, como um continuador de Agostinho, com a grande diferença, porém, de que Rousseau busca a fonte da unidade e da totalidade no próprio eu e, por isso, pode ser considerado um autor eminentemente moderno.

0 primeiro sentimento que provém da natureza é correto e trata-se do sentimento do amor de si mesmo (amour de soi-même), que está em nós e é responsável para que sejamos nós mesmos. A voz interna da natureza determina em última instância o que é bom. A consciência, por sua vez, que é nossa condutora interna, fala para nós na linguagem da natureza. Ela é a voz da natureza como aparece num ser que já vive em sociedade, que é capaz de linguagem e razão. Esse é um dos motivos que levaria Rousseau atribuir grande peso ao papel da consciência, pois ouvir sua voz interna significaria nada mais do que ouvir a própria voz da natureza. Nessa identificação, entre natureza e consciência, repousaria o núcleo constitutivo do sujeito agente, a partir do qual ele constrói suas referências normativas de autenticidade e de personalidade própria, alcançando então a condição de ser ele mesmo (isto é, de ter um Self autônomo). Nesse contexto, segundo Taylor, o que Rousseau considerou como sendo o viver de acordo com a natureza seria viver de acordo com a voz interna da consciência e isso representaria a busca constante empreendida pelo nascente homem moderno de ser coerente consigo mesmo. Esse esforço rousseauniano de tematizar a ligação do homem com a natureza e de destacar a dimensão natural tanto do homem como da sociedade poderia ser interpretado também como uma crítica à autodeterminação calculista e alienada da racionalidade moderna, e tal crítica deveria ser levada adiante pela tematização da relação entre natureza e consciência (Taylor, 1996).

Para os propósitos de Taylor, de investigar as fontes conceituais da formação do Self, é central a analogia rousseauniana entre voz interna da natureza e voz interna da consciência. No entanto, apesar de muito sugestiva, essa sua interpretação passa por alto algumas das principais dificuldades que emergem dessa analogia. Taylor não trata sistematicamente, por exemplo, do significado dos conceitos de razão e consciência e de sua relação, no contexto argumentativo de Rousseau, com o conceito de natureza. Ora, a questão é se se pode discutir adequadamente o pensamento de Rousseau, analisando sua contribuição para o surgimento da identidade moderna a partir da conexão entre os conceitos de natureza e consciência, sem tratar sistematicamente dos problemas relacionados ao conceito de razão e de sua relação com o conceito de consciência. Qualquer tentativa, ao meu ver, que ignora esse ponto, como a de Taylor, só pode oferecer uma imagem muito generalizante e parcial das 'fontes do si mesmo e do surgimento da identidade moderna'.

Que o pensamento de Rousseau tem contribuído, no entanto, para oferecer uma 'autocertificação da modernidade' é o que pretendo mostrar na seqüência com base na hipótese de que a capacidade de 'sair fora de si mesmo', latente, mas não desenvolvida, da ação humana movida pelo sentimento do amourpropre só é capaz de ser levada adiante com maior consistência por meio de uma teoria da determinação racional da vontade, a qual Rousseau esboça, sem desenvolvê-la adequadamente, no livro IV do Émile. Ele não pode justificá-la adequadamente porque vacila no 
esclarecimento dos conceitos de razão e de consciência e não é firme o suficiente para mostrar que sem o confronto com a razão, a voz interna da consciência não pode adquirir conteúdo moral. Por não poder justificar adequadamente sua teoria da determinação racional da vontade, também não pode tirar todas as conseqüências do recurso ao si mesmo (Self) como uma nova instância de legitimação da moralidade das ações sociais do homem moderno. Apesar dessas dificuldades, procuro adotar uma posição que possa colocar as idéias de Rousseau sobre a relação entre razão e consciência, ainda que confusas e obscuras, a favor de um projeto de educação natural.

Para que o conceito de natureza de Rousseau possa se tornar, no entanto, um conceito eminentemente moderno, ele precisa se defrontar ao menos com um dos problemas de teodicéia, a saber: com o problema da origem da maldade na história da vida humana e poder, mostrar que a sua culpa não reside em Deus nem exclusivamente no homem, mas sim na sociedade. Ele precisa mostrar, em primeiro lugar, que o sentido normativo do conceito de natureza não depende mais diretamente de Deus, para poder conectar, em seguida, a sua voz com a voz interna da consciência. Amparandome em Cassirer (1980), vou reconstruir em largos traços o argumento com o qual Rousseau enfrenta esse problema de teodicéia e delinear a solução por ele apresentada. Na seqüência, amparando-me em passagens da 'Profissão de fé do vigário saboiano', vou reconstruir os argumentos relacionados ao problema da determinação racional da vontade, procurando mostrar que Rousseau justifica-o por meio da tentativa de conectar o seu conceito normativo de natureza com a voz interna da consciência. Esse passo em seu argumento não ocorre sem maiores dificuldades: primeiro, a expressão 'voz interna da consciência' parece carregar um claro hibridismo, pois, no fim da exposição do vigário saboiano, considerando o caráter obscuro da voz da consciência, assumindo simultaneamente a condição de ser 'instinto divino' e desdobra- mento da racionalidade moral humana, não ficamos sabendo ao certo o quanto ela contém de humano e o quanto mantém de divino; justamente esse hibridismo é uma das razões que ajuda explicar a incompletude de sua teoria da determinação racional da vontade. Por último, mesmo considerando essas e outras dificuldades, procuro extrair breves conclusões sobre o significado que o esboço de uma teoria da determinação racional da vontade assume em relação ao projeto educacional do Emílio.

\section{Modernidade e teodicéia: desresponsabilização de Deus e culpabilização da sociedade}

Como um autor do século XVIII, Rousseau tem diante de si a tarefa de pensar o homem como um ser livre para conduzir sua ação, tomar suas decisões e ser responsabilizado por elas. Do ponto de vista filosófico, isso significa poder justificar a tese de que a vontade humana é capaz de se determinar racional e livremente, independente de forças externas e estranhas a ela. Visto sob essa perspectiva, o iluminismo de Rousseau coloca-se diante de um duplo desafio: poder basear-se, por um lado, num nível de argumentação racional que possa evitar, simultaneamente, tanto o excesso como o déficit de racionalidade. lsto é, ele precisa sustentar um conceito de razão que não seja excessivamente otimista nem pessimista. Por outro lado, deve mostrar que a capacidade racional humana, evitando tanto seu excesso como sua falta, é capaz de justificar, por si mesma, a ação humana em sua coletividade, tratando reflexivamente (conceitualmente) de seus dilemas morais e de sua destinação. Rousseau vê-se na eminência de ter que explicar a origem dos juízos de valor, das noções de bem e de mal na ação histórico-social do homem, sem poder fazer concessão à interferência direta do poder divino na determinação do conteúdo dessas noções. Isto é, seu problema consiste em tratar das condições de possibilidade de ações boas e más, portanto, do problema da moralidade, sem poder contar mais com a interferência de Deus. Para 
ele, a questão não se coloca mais, por exemplo, no sentido de discutir a relação da moralidade das ações humanas com o poder divino e de saber como o conceito de um Deus perfeito e justo pode ser compatível com a imperfeição e maldade humanas, mas independentemente disso, ter que explicar a bondade e a maldade das ações humanas, enraizadas na vida histórico-social do homem, como responsabilidade direta de suas decisões.

Será, sobretudo, sua tentativa de tratar da moralidade humana que Rousseau, ao romper com uma abordagem tradicional dos problemas de teodicéia, oferece um diagnóstico filosófico extremamente original dos 'novos tempos' e, por assim dizer, insere-se numa tradição iluminista que prima pela 'dialética da razão'. A abertura para a tematização da problemática da subjetividade moderna, isto é, da busca do indivíduo em construir a identidade do seu eu consigo mesmo, mediante a racionalidade emergente de sua própria sociabilidade, é alcançada por meio do enfrentamento com problemas de teodicéia. Como mostra Cassirer (1980), tanto sua crítica à cultura como à sociedade está profundamente influenciada por tais problemas que são próprios aos séculos XVIl e XVIll, estando sua crítica conectada com o problema do mal e, especificamente, como o problema do 'mal social'. Rousseau proclama, por um lado, a doutrina da bondade original da natureza humana, fazendo dela o centro e o eixo de seu pensamento. Por outro lado, afirma a perversão e a corrupção dessa bondade no processo de sociabilidade humana. Nesse contexto, coloca-se a pergunta de como se pode atribuir o mal e a culpa à natureza humana se ela está livre de ambos em seu estado natural? Ora, se o mal não é causado pela natureza humana original nem por Deus, uma vez que Rousseau o desresponsabiliza dessa causa, de onde ele provém então? Rousseau debate-se com esse problema e a solução encontrada por ele mostra a originalidade de seu diagnóstico sociofilosófico da nascente modernidade.

A originalidade da resposta de Rousseau sobre a origem do mal consiste não em concebê- lo como obra de Deus nem como obra exclusiva do homem individual, mas principalmente como obra de sua sociabilidade: Deus não tem nada a ver com nossas irresponsabilidades morais por um lado e, por outro, minha própria bondade natural ainda não pode ser responsabilizada pela maldade das ações humanas simplesmente por que ela é uma bondade ainda não sociável e, portanto, ainda incapaz de conteúdo moral ${ }^{1}$. Essa é, de modo geral, uma tendência em seu pensamento, manifestada tanto no Segundo discurso como também no Contrato social. No entanto, há, segundo Cassirer (1980), uma diferença notável entre as duas obras: enquanto o Segundo discurso defende a idéia de que o ingresso na sociedade significa um abandono do estado feliz da natureza (da bondade natural), pois o homem pensante é visto como um animal desnaturado ('o homem que medita é um animal depravado'), o Contrato social afirma que o "espírito humano alcançou a verdadeira liberdade na ordem do mundo político e social" (p. 397). Enquanto o primeiro concebe o processo de socialização como uma perda da liberdade natural e, portanto, como sinônimo do aumento do nível de artificialidade e convencionalismo das relações humanas, o Contrato social vê em tal processo a condição de possibilidade para que o homem possa desenvolver suas faculdades e, em síntese, regrar sua própria sociabilidade ${ }^{2}$. No entanto, o que explicaria então uma mudança de enfoque dessa envergadura?

Tal mudança deve-se, ao meu ver, fundamentalmente a um novo significado atribuido ao conceito de liberdade pelo Contrato social em relação ao Segundo discurso: ao procurar tratar da origem das desigualdades sociais, buscando radicá-la na propriedade privada, Rousseau ampara-se, no Segundo discur-

1. Essa interpretação do conceito de bondade natural em Rousseau também é enfatizada por Fichte (1978) em sua Sittenlehre, para quem a maldade e a bondade humanas repousam, no sentido moral, no ato racional livre do ser humano, o qual pressupõe, por sua vez, a superação daquela bondade original e ingênua. 0 que Fichte exige é que Rousseau deveria ter concedido mais à razão e menos à consciência e é justamente no contexto dessa exigência que se pode entender sua afirmação de que Rousseau "atua sem ter consciência de sua própria atividade” (Fichte apud Guéroult, 1972, p. 161).

2. Kersting (1994) também traça uma diferença semelhante a nós entre esses dois livros. 
so, mais no conceito natural e, portanto, ainda não definitivamente moral e jurídico de liberdade. Já no Contrato social, predomina o conceito de liberdade 'bem regrada' (la liberté bien réglée) que é o ponto de partida da indispensável consciência que cada cidadão deve ter de seus limites, isto é, da consciência sobre até onde vão seus direitos e onde estão seus deveres, consciência essa que é indispensável para viabilizar uma boa sociabilidade. No Segundo discurso, não se coloca com toda a clareza ainda a tese da base social da moralidade que sustenta a teoria social subjacente tanto ao Contrato social como ao Émile (Dalbosco, 2005). É tal tese e, com ela, o conceito de liberdade 'bem regrada' que permite Rousseau analisar o processo de sociabilidade humana como origem de sua maldade e, ao mesmo tempo, como possibilidade de sua correção. Ora, é no contexto de tal conceito que ele pode chegar ao problema da relação entre liberdade e lei, colocando-se como defensor da lei e de sua validade universal incondicional. Quando visto sob essa perspectiva, então, o pensamento de Kant seria imensamente tributário do pensamento rousseauniano, tendo sido ele um dos poucos filósofos que se tornou discípulo e admirador de Rousseau (Cassirer, 1980).

Do Segundo discurso ao Contrato social, também ocorre uma inversão de significado em relação aos conceitos de estado de natureza e estado social: enquanto no Segundo discurso o estado de natureza é visto como fonte da bondade natural humana e o estado social como fonte de sua perversão, no Contrato social o estado social é associado, direta e positivamente, à possibilidade de superação do nível instintivo e, portanto, desregrado da vida humana em seu estado natural. Esse ponto de vista é justificado claramente numa passagem do Contrato social:

Esta passagem do estado de natureza (l'état de nature) para o estado social (l'état civil) provoca no homem uma mudança muito notável, substituindo, na sua conduta, o instinto (l'instint) pela justiça (justice) e atribuindo às suas ações a moralidade (moralité) que antes lhe faltava. É só então que, tomando a voz do dever (la voix du devoir) o lugar do impulso físico (l'impulsion physique), e o direito o lugar do desejo, o homem, até aí levando em consideração apenas sua pessoa, vê-se forçado a agir baseando-se em outros princípios e a consultar a razão antes de ouvir suas inclinações. (OC iii 364) (1978, p. 36; 2003, S. 22) 3 $^{3}$

0 pessimismo presente na primeira obra referente à análise do processo de socialização humana é substituído, no Contrato social, pela ênfase nas conquistas que o ingresso humano na sociedade adquire: na medida em que o impulso físico é submetido ao dever, o direito passa a regular os desejos e a razão humana domina suas inclinações. Assim, o Contrato social representa a perspectiva de que quanto mais o ser humano se socializa, tornando sua ação cada vez mais racional e livre, embora não necessariamente moral, tanto mais sua dimensão impulsiva e desejante é colocada sob o controle da racionalidade moral e jurídica e o aumento progressivo de sua socialização corresponde, portanto, à intensificação da dimensão moral e jurídica de sua ação.

Voltemos ao nosso ponto. Do problema de Deus, passamos para o problema da origem do mal no mundo, localizando-a na própria sociedade. No entanto, o percurso do pensamento de Rousseau não se esgota aí. Se o mal reside na sociedade, precisamos um critério justo e adequado para julgá-lo e ele aponta a subjetividade e a interioridade humanas como núcleo desse julgamento. Entretanto, trata-se de uma subjetividade que deve agora buscar a

3. Todas as citações das obras de Rousseau, salvo indicação contrária, serão feitas como a que seguiu, indicando-se no corpo do próprio texto, de acordo com a edição Gallimard da Bibliothèque de la Plêiade, a abreviatura $\mathrm{OC}$ referente às Oeuvres Complètes, seguida da indicação do volume em romano minúsculo com a respectiva paginação em arábico. A citação no corpo do texto será seguida, imediatamente, por uma indicação entre parênteses, primeiro, da tradução portuguesa e, depois, da tradução alemão, indicando-se tão somente 0 ano e a paginação correspondentes à tradução usada para o cotejo com o texto original. Usei amplamente as traduções portuguesas dos textos de Rousseau, fazendo livremente as modificações quando julguei necessárias. 
racionalidade normativa nela mesma, considerando, no entanto, que tal racionalidade também é, desde o início, constituída socialmente. Parece que nos vemos aqui inserido numa ordem circular entre racionalidade e sociabilidade! De qualquer modo, a guinada do divino para o social não resolve de modo algum o problema, uma vez que o ser humano, liberto do poder de Deus, encontra-se aprisionado socialmente: livre do fetiche divino, não está livre do estranhamento social.

A busca pela autonomia, que passa inicialmente pela independização do homem em relação ao poder religioso exercido temporalmente pelo clero, vê-se confrontada novamente com um tipo de alienação mais profunda, que se radica na própria natureza antropológica do ser humano e que se efetiva nas mais diversas formas de relacionamento social e não só no relacionamento religioso. Trata-se da tendência humana, brilhantemente exposta nas passagens do livro IV de Émile que antecedem a 'Profissão de fé do vigário saboiano', de querer construir a identidade consigo mesmo por meio da comparação com os demais. É esse ‘ato imitativo', de caráter profundamente fetichizante, que outrora se manifestava na relação do ser humano com sua divindade, que se manifesta agora, no contexto de uma sociedade cada vez mais secularizada, na relação entre os seus próprios membros, constituindo o caráter artificial e inautêntico de sua identidade. A tendência de se comparar com os outros tem sua origem, conforme mostra Rousseau, no sentimento egoísta do amour-propre, o qual, por sua vez, nasce com a própria sociabilidade humana.

Ora, se a origem do mal humano e social não reside em Deus, uma vez que Ele é a perfeição e o absoluto em bondade, nem exclusivamente no homem, porque em seu estado natural ele não conhece a maldade, ela só pode ter sua origem na sociedade. A solução dada por Rousseau ao problema da teodicéia consiste em dizer que a sociedade é a responsável pela criação e, ao mesmo tempo, pela solução de seus problemas. A solução de Rousseau consiste, portanto, segundo Cassirer
(1980), "em tirar de Deus o peso da responsabilidade e colocá-lo na sociedade humana. Se a sociedade não pode suportar esse peso, se não consegue realizar, através da responsabilidade livre, e que sua autodeterminação exige dela, ela é culpada” (p. 413). Essa solução coloca o problema da responsabilidade num lugar não visto antes por ninguém, deslocando o eixo da 'imputabilidade' das ações do sujeito individual para o sujeito coletivo, isto é, para a sociedade. Vista sob a perspectiva antropológica, a origem do mal não reside no sentimento do amour de soi-même, mas sim no sentimento de amour-propre:

0 amor-próprio, que contém a causa de toda a futura perversão e fornece a vaidade do homem e sua sede de poder, deve ser imputado exclusivamente à sociedade. (p. 411)

Um dos problemas que permanece nessa solução, e que não é visualizado por Cassirer, é o de saber se uma teoria da sociedade que parece desresponsabilizar o sujeito individual da maldade no mundo e responsabilizar inteiramente a sociedade pode dar conta da imputabilidade das ações individuais? Justamente para evitar que a individualidade seja sufocada ou aniquilada pela sociedade e evitar deixar com isso o problema da imputabilidade individual das ações em aberto, problema esse que é de fundamental importância para as teorias moral e jurídica, é que, ao meu ver, o argumento de Rousseau precisa de uma teoria da determinação racional da vontade, que seja capaz de pensar a autonomia do indivíduo em seu processo de socialização. Embora Rousseau também não tivesse inteiramente consciência desse problema, ele esboça tal teoria na 'Profissão de fé do vigário saboiano', intercalandoa na exposição do livro IV do Émile. Em que medida ela dá conta satisfatoriamente dessa dupla tarefa, isto é, da tarefa de pensar o problema da imputabilidade das ações individuais e de justificar a autonomia do indivíduo, é o que veremos a seguir. 


\section{Determinação racional da vontade humana: da voz da natureza à voz interna da consciência}

Para que uma teoria da obrigação moral possa ser a base de figurações jurídico-políticas e sustentar o processo pedagógico da educação natural, ela deve estar embasada por uma teoria da determinação racional da vontade, da qual, como afirmei, Rousseau oferece um esboço no livro IV de Émile. Seu ponto de partida consiste em desvincular a vontade da sensibilidade, tornando-a independente em relação aos sentidos e colocá-la sob o domínio da razão. Interpretado sob essa perspectiva, Rousseau antecipa a temática kantiana da fundamentação da moralidade na Grundlegund ${ }^{4}$, na qual, a razão deve determinar a vontade por motivos a priori. No entanto, Rousseau não está plenamente convencido, no livro IV do Émile, como Kant o está na GMS, sobre a necessidade da determinação racional da vontade como ponto de partida indispensável para uma fundamentação adequada da moralidade das ações humanas. Seu argumento vacila, tornando-se confuso em relação ao significado do conceito de razão e consciência e o papel que desempenham na justificação da moralidade.

Por um lado, parece haver uma direção clara no sentido de atribuir à razão a capacidade de determinar a vontade. Diz Rousseau: "Quando me perguntam qual é a causa que determina minha vontade, eu me pergunto qual a causa que determina meu julgamento: porque é claro que estas duas coisas não são senão uma” (OC iv 586) (1992, p. 324; 2004, S. 573). Ao identificar a causa da determinação da vontade com a causa da determinação do julgamento, seu argumento está autorizando a conclusão de que a vontade é determinada ou, pelo menos, pode ser determinada pela razão. Na seqüência, ainda no mesmo parágrafo, ele formula literalmente a tese da determinação racional da vontade: "Qual a causa então que determina sua vontade (volonté)? E qual a cau- sa que determina o seu julgamento (jugement)? É sua faculdade inteligente (faculté intelligente), seu poder de julgar; a causa determinante está em si mesmo. Além disto não entendo mais nada" (OC iv 586) (1992, p. 324; 2004, S. 573). Ao colocar o problema nesses termos, Rousseau está evidenciando com toda a clareza uma 'consciência de época' dos 'tempos modernos' e isso não significa outra coisa senão apresentar uma teoria de autocertificação da modernidade sustentada por uma teoria da determinação racional da vontade: sua causa reside não mais em um Deus nem mais num conceito de Ser, mas na 'capacidade própria de conhecimento', isto é, na capacidade da própria razão humana. Ao dizer que a causa determinante da vontade está no 'si mesmo', Rousseau bloqueia qualquer acesso externo, concebendo o recurso ao 'si mesmo' como princípio fundante - como causa - da determinação da vontade. Se esse é o resultado a que chega o seu argumento, ainda que possa ser um resultado provisório, cabe perguntar o que significa a vontade ser determinada pelo 'si mesma' e, mais especificamente, o que significa esse 'si mesmo'? Para ser coerente com a exigência posta pelo seu argumento até aqui, o próprio 'si mesmo' deveria ser constituído racionalmente ou, pelo menos, o argumento de Rousseau deveria oferecer um 'acesso racional' ao 'si mesmo', para que ele pudesse ser a causa determinante da vontade. Antes de tratarmos dessa dificuldade, é preciso seguir mais de perto sua argumentação em relação ao problema da liberdade da vontade.

Consciente de que não pode existir 'uma verdadeira vontade sem liberdade', Rousseau conecta esse esboço da determinação racional da vontade com o problema da liberdade: se a minha vontade deve ser determinada racionalmente, para que tal determinação possa ser eficiente, precisa ser uma determinação livre, isto é, ocorrer mediante a idéia da liberdade. Por isso, a determinação racional da vontade

4. Forma abreviada da obra kantiana Grundlegung zur Metaphisyk der Sitten, também conhecida pela sigla GMS. 
deve sintetizar a capacidade do querer por mim mesmo, sem o recurso a qualquer determinação estranha: "mas minha liberdade (liberté) consiste nisto mesmo que só posso querer o que me é apropriado ou o que julgo adequado, sem que nada do que venha de fora de mim me determine" (OC iv 586) (1992, p. 324; 2004, S. 573-574). lsso aponta para o critério de que uma escolha só pode ser considerada como acertada se for resultado de um querer orientado pelo julgamento. Sendo um ponto de partida indispensável para se chegar à justificação da autonomia moral do indivíduo, o critério da determinação racional e livre do querer ainda está muito longe, no entanto, de se constituir num critério universal, válido para todos. Embora já se comece desenhar com essa argumentação o núcleo constitutivo do próprio conceito de vontade geral, pois seria um absurdo querer pensá-lo sem o conceito de uma vontade autodeterminada, isto é, sem o conceito de uma vontade racional e livremente constituída, o problema reside em ter que assegurar que o conteúdo daquilo que é 'julgado como adequado' pelo ‘si mesmo' não seja apenas representação de interesses privados de uma vontade individual egoísta. Ou seja, não há ainda um critério para se saber ou se evitar que aquilo que eu julgo como apropriado (no sentido de ser autêntico e merecedor de crédito) não seja apenas uma conveniência pessoal minha que, além de não ir ao encontro do bem comum, pode estar inclusive em pleno desacordo com ele.

Para poder agir, o ser humano precisa ter uma vontade e uma liberdade. Ou seja, Rousseau esboça uma teoria da ação no livro IV do Émile que tem na liberdade da vontade do ser humano o seu princípio. Isso ele afirma literalmente na seguinte passagem: "O princípio de toda a ação está na vontade de um ser livre; não se poder regressar além disto" (OC IV 586) (1992, p. 324; 2004, S. 574). Se "não se pode ir além disso', podemos nos perguntar se com essa afirmação ele já não teria ido longe demais? Ou seja, qual é o argumento para justificar a liberdade da vontade humana? Como posso saber que minha vontade é livre, se a todo o momento pareço vê-la subordinada a uma infinidade de outras determinações que são estranhas a ela mesma? A independência em relação aos sentidos seria um critério suficiente para assegurar sua liberdade? No entanto, para uma vontade que fosse inteiramente livre da pressão das paixões e da força da sensibilidade, teria sentido ainda em falar de liberdade? Ao meu ver, Rousseau não oferece uma resposta plausível para essas questões no contexto argumentativo da 'Profissão de fé do vigário saboiano', mesmo considerando que tal escrito seja o tratamento mais sistemático que ele ofereceu de sua filosofia moral. 1sso mostra então o nível precário contido, no geral, pelo seu esboço de teoria da determinação racional da vontade.

De qualquer forma, seu esforço consiste em sustentar tal esboço em três artigos de fé e também fazer depender deles o conteúdo subseqüente de sua argumentação. 0 primeiro atribui a causalidade da ação à vontade, isto é, afirma que não pode existir ação sem vontade: "há uma vontade que move o universo e anima a natureza" (OC iv 576) (1992, p. 315; 2004, S. 560) e a matéria em movimento é prova dessa vontade. 0 segundo mostra que uma matéria em movimento, isto é, uma ação, só pode ser considerada como inteligente quando orientada por leis: "Se a matéria em movimento me mostra uma vontade, a matéria em movimento segundo certas leis mostra-me a uma inteligência" (OC iv 578) (1992, p. 317; 2004, S. 562). Por fim, o terceiro artigo de fé faz a vontade humana depender de sua liberdade. Em síntese, seu argumento conecta a ação a uma vontade e esta, à racionalidade e à liberdade, permitindo que se conclua a idéia de que se o agir mediante leis mostra-me a racionalidade da vontade, colocando-a também na base de minha própria liberdade, então somente uma vontade racionalmente livre é capaz de agir segundo a representação de leis. Ter-se-ia alcançado aqui então um passo irretrocedível para a discussão da moralidade das ações hu- 
manas. Se o argumento de Rousseau tivesse concluído enfaticamente nessa direção, ele teria também antecipando literalmente outra tese central da GMS, a saber, de que somente seres racionais e livres podem agir de acordo com a representação de leis. No entanto, mesmo que ele não tenha chegado claramente a essa conclusão, ela se coloca como condição indispensável para que indivíduos possam lavrar livremente contratos entre si e se sintam obrigados, racional e livremente, a viver mediante ordenamentos de uma vontade geral.

Se Rousseau tivesse enfatizado satisfatoriamente a racionalidade e a liberdade da vontade humana, com isso ele ainda não teria mostrado a moralidade dessa mesma vontade, uma vez que uma vontade racionalmente livre não pode ser identificada com uma vontade moral. Como Kant mostrará duas décadas depois, a moralidade não pode ser deduzida analiticamente da liberdade da vontade humana. No caso de Rousseau, não se trata ainda, portanto, de uma vontade moral, pois mesmo quando impulsionada pela razão a agir livremente, não está garantido ainda que a vontade vai agir moralmente. Entretanto, o que falta então para que uma vontade racionalmente livre também seja moral? Ao se colocar a pergunta nesses termos, Kant responderá dizendo que a moralidade da ação de um ser, que é racional e ao mesmo tempo sensível, portanto, de um ser que não pode determinar racionalmente de uma forma absoluta sua vontade, só é possível na medida em que a lei moral valha para ele na forma de um dever, isto é, na linguagem técnica da GMS, somente na medida em que a lei moral tenha validade para esse ser na forma de um imperativo categórico e, para assegurar isso, é preciso uma dedução. No entanto, Rousseau não só não formula expressamente a lei moral, como, muito menos, terá condições de pensar numa dedução. Suas dificuldades aumentam ainda mais quando ele vê no recurso à voz interna da consciência o critério de julgamento da moralidade das ações humanas, pois, ao fazer isso, ele assume o ônus da prova de ter que ao menos apresentar uma re- lação satisfatória entre as dimensões sensíveis e racionais do ser humano, uma vez que a própria capacidade de julgamento pertence à razão. $\mathrm{Ou}$ seja, em tese, seria ela que permitiria, em termos de moralidade, o acesso mais promissor à voz interna da consciência.

Embora Rousseau possa ser interpretado como um precursor de Kant, não é necessário exagerarmos numa 'kantianização' de seu pensamento. Portanto, prossigamos: antes de chegar ao argumento da consciência, como vimos, Rousseau precisou mostrar que os males e problemas vividos pelo homem são de responsabilidade da sociedade e, em parte, do próprio homem. Isto é, ele precisou, primeiramente, desresponsabilizar a Providência. Seu argumento joga-nos inteiramente na condição de ter que responder pelos nossos próprios atos, sem poder querer mais justificar que o mal que nos acomete, que a condição miserável na qual nos encontramos seja obra do destino ou da vontade de Deus, mas que depende do próprio 'abuso de nossas faculdades'. Ao desresponsabilizar a Providência de nossos males, Rousseau parece, ao mesmo tempo, não querer deixar-nos órfão dela: "Ela [a Providência, CAD.] não quer o mal que o homem faz, abusando da liberdade que ela the dá; [...]. Ela o quis livre, a fim de que fizesse, não o mal, mas o bem de vontade própria” (OC iv 587) (1992, p. 325; 2004, S. 574). Ao desresponsabilizar a Providência e ao voltarse especificamente para o homem e para a sociedade, ele prepara o terreno para um outro tratamento do problema da imputabilidade moral: porque possuímos uma vontade livre que é capaz de se deixar influenciar pelas paixões, mas que também pode se determinar racionalmente, podemos escolher entre fazer o bem ou o mal e, fundamentalmente, sermos responsabilizados pela nossa escolha. Diz ele: "Homem, não procurais mais o autor do mal; és tu mesmo esse autor. Não existe outro mal senão o que fazes e sofres, e um e outro te vêm de ti”. Em outra passagem, na mesma página, ele afirma: "0 mal moral é incontestavelmente nossa obra" (OC iv 587) (1992, p. 325; 2004, S. 575). 
Se precisamos ser responsáveis pela moralidade de nossas ações, o ponto de partida para discuti-la também deve residir em nós mesmos e essa é a guinada decisiva provocada por seu pensamento: de agora em diante, toda a moralidade de nossas ações dependerá do julgamento que fazemos de nós mesmos e é na voz interna da consciência que buscamos o critério inato de justiça e virtude para efetuarmos esse julgamento. Rousseau define a consciência da seguinte maneira: "Há, portanto, no fundo de nossas almas um princípio de justiça e de virtude de acordo com o qual, apesar de nossas próprias máximas, julgamos boas ou más nossas ações e as de outros e é a esse princípio que chamo de consciência (conscience)" (OC iv 598) (1992, p. 335; 2004, S. 590). Ela é a sede dos sentimentos que nos permitem discernir o "adequado ou inadequado que existe entre nós e as coisas que devemos respeitar ou evitar" (OC iv 599) (1992, p. 337; 2004, S. 592). Todo o peso atribuído à consciência como sede da moralidade revela-se com toda a inteireza numa conhecida passagem da 'Profissão de fé do vigário saboiano', na qual Rousseau exclama:

Consciência! Consciência! (conscience!) Instinto divino, voz celeste e imortal; guia seguro de um ser ignorante e limitado, mas racional e livre; juiz infalivel do bem e do mal, que tornas o homem semelhante a Deus, és tu que fazes a excelência de sua natureza e a moralidade de suas ações; sem ti nada sinto em mim que me eleve acima dos animais, a não ser o triste privilégio de me perder de erro em erro com a ajuda de um entendimento (entendiment) sem regra e de uma razão (raison) sem princípios. (OC iv 600-601) (1992, p. 338; 2004, S. 593-594)

Rousseau a concebe como juiz e guia que distancia o homem dos animais e o aproxima de Deus; enfim, ela é o critério básico apontado por ele para distinguir entre o mal e o bem e para avaliar a moralidade de nossas ações.
Há no mínimo duas dificuldades centrais conectadas com essa 'teoria da consciência': a primeira é a da sua compatibilidade com a tese oriunda da teoria social de Rousseau sobre a base social de nossa moralidade; a segunda diz respeito à sua compatibilidade com o esboço da teoria da determinação racional da vontade. Quanto à primeira dificuldade, ela pode ser mais bem formulada com a seguinte pergunta: sendo o recurso à voz interna da consciência o critério para o julgamento moral e considerando que Rousseau a define como o princípio inato de justiça e de virtude, como ela se relaciona com a base social da moralidade? Isto é, em que sentido esse seu inatismo é compatível com o caráter social da moralidade das ações humanas? Há aqui, numa primeira vista, uma contradição explicita no pensamento de Rousseau. No entanto, uma outra passagem parece oferecer um argumento plausível para tratar dessa contradição. Diz Rousseau:

Mas se, como não se pode duvidar, o homem é sociável (sociable) por sua natureza, ou ao menos feito para sê-lo, ele só o pode ser através de outros sentimentos inatos, que se referem à espécie; pois, em se considerando unicamente a necessidade física, devese com certeza separar um dos outros os homens ao invés de aproximá-los. Ora, é do sistema moral (sistême moral) formado por essa dupla relação consigo mesmo e com suas relações com seus semelhantes que nasce o impulso da consciência. (OC iv 600) (1992, p. 337; 2004, S. 592)

Ela relativiza, na primeira parte, o sentido do inatismo: Rousseau afirma que a predisposição humana para a sociabilidade depende de sentimentos inatos. 0 inato pode ser compreendido aqui biologicamente como uma predisposição genética da espécie que a impele, não só por motivos de autoconservação, para a sua socialização. Na seqüência, vem o argumento decisivo: embora o seu princípio de justiça e de virtude seja inato, a consciência 
recebe seu impulso, além de sua relação consigo mesma, também da relação com seus semelhantes. Portanto, há uma predisposição natural que é impulsionada socialmente e isso parece então não contradizer a tese da sociabilidade da moral.

A segunda dificuldade, além de mais importante, é mais grave. Se a consciência passa a ser o critério de julgamento de nossas ações, como ela se relaciona com nossa vontade e, mais precisamente, com aquela necessidade, identificada por Rousseau, de uma determinação racional da vontade, põem-se aqui de imediato algumas perguntas: em que sentido o recurso à voz interna da consciência constitui critério adequado para uma vontade que busca agir moralmente? Se, como vimos, Rousseau considera importante que a vontade seja determinada racionalmente, qual é o grau de reflexividade que a voz interna da consciência permite alcançar? Enfim como ela se relaciona com a razão?

Parece-me que o ponto de partida para um tratamento adequado dessa segunda dificuldade e as perguntas dela derivadas consiste, primeiro, em não perder de vista a distinção feita por Rousseau entre consciência e razão: se é com a primeira que nós podemos sentir, será somente com a segunda que alcançamos nossa capacidade de julgamento. Segundo aspecto, como decorrência do primeiro, se a consciência não possui a capacidade de julgamento, ela precisa ser esclarecida pela razão. É evidente que essa interpretação coloca-se, em certo sentido, na contramão de muitas afirmações de Rousseau e, sobretudo, à sua insistência quanto à não subordinação excessiva da consciência à razão. Entretanto, é preciso ter em mente também o fato de que essa sua posição deve-se em grande parte à sua crítica aos sistemas filosóficos abstratos e ao próprio conceito de razão deles decorrente. Por ser contra todo o tipo de intelectualismo moral, Rousseau atribui grande peso ao recurso à consciência e à sensibilidade para o tratamento dos problemas morais. Em síntese, suas convicções intelectuais caminham firmemente na direção de reconhecer o apelo ao coração humano como uma referencia indispensável a um tratamento realista da moralidade humana. É a partir disso que se pode compreender também sua grande ênfase, no método pedagógico, ao apelo do coração:

Não te aproximes jamais da juventude com argumentações racionais secas. Daí um corpo à razão se quiserdes lha torná-la sensível. Fazei passar pelo coração a linguagem do espírito, a fim de que se faça entender. (OC iv 648) (1992, p. 382; 2004, S. 657)

No entanto, seu apelo excessivo à voz da consciência e aos sentimentos do coração dificulta, por vezes, a própria compreensão de seu conceito de razão. Segundo Schäffer (2002), Rousseau concebe-a como um poder (faculdade) ambivalente: a razão é, por um lado, a produtora de erros, por estar subordinada às paixões e ao amor-próprio. No entanto, ela é também, por outro lado, aquela força voltada para o controle das paixões e que está na condição de conhecer o bem. 0 mais fundamental em seu conceito de razão residiria, segundo esse autor, na idéia de que a razão indicaria para o seu corretivo imediato, ou seja, para a consciência e somente quando relacionada a ela é que a razão poderia livrar-se de suas incorreções. Por fim, Rousseau tem como pano de fundo da educação do jovem Emílio essa necessária relação entre consciência e razão.

Rousseau apresenta, ao meu ver, um conceito menos problemático de razão, que é mais compatível com o projeto educacional de Emílio, quando trata, no livro 11 do Émile, justamente da importância de se desenvolver a sensibilidade na formação da criança. Aí afirma ele o seguinte: "De todas as capacidades do homem, a razão, que não é, por assim dizer, senão um composto de todas as outras, é a que se desenvolve mais dificilmente e mais tarde" (OC iv 317) (1992, p. 74; 2004, s. 205). Considerando que a capacidade de julgamento deve ser provocada, em sua inteireza na formação de Emílio, somente mais tarde e considerando as 
dificuldades subjacentes ao desenvolvimento desta capacidade, Rousseau pensa que a melhor forma de prepará-la é começar a educação pela sensibilidade. Na verdade, o que está em jogo é a idéia de que, embora discorde do conceito de razão dos filósofos, ele considera central a capacidade de julgamento à educação de Emílio, sobretudo em relação à sua formação moral, assumindo, desse modo, a tese de que a voz da consciência precisa ser confrontada com a razão. Entretanto, o que essa tese significa exatamente e que dimensão ela assume para se pensar a moralidade das ações humanas parecem ser questões que Rousseau não tematizou com a atenção e sistematicidade merecidas, e essa foi uma das razões que o impossibilitou de oferecer uma teoria sistemática da determinação racional da vontade humana.

Encontramo-nos aqui, sem dúvida, no âmago de um dos pontos mais controversos na interpretação de seu pensamento, pois, além de não definir claramente os conceitos de consciência e de razão, Rousseau também não foi claro o suficiente ao pensar a relação entre ambos, abrindo margens para muitas especulações. Apesar disso, penso ser possível verter seu pensamento contra si mesmo e, por meio do confronto de passagens contraditórias, reconstruir um conceito de educação natural que justifique a responsabilização dos envolvidos no processo pedagógico, a qual só pode ser assegurada com base no fortalecimento da tese de que a voz da consciência precisa ser submetida, sob determinadas circunstâncias e mediante determinados aspectos, aos preceitos da razão. Tal fio condutor, apesar da obscuridade da argumentação de Rousseau, encontra-se confirmado na seguinte passagem do livro 1 do Émile:

Somente a razão (raison) nos ensina a conhecer o bem e o mal. A consciência (conscience) que nos faz amar um e odiar o outro, embora independente da razão, não pode, pois, desenvolver-se sem ela. Antes da idade da razão (l'age de raison), fazemos o bem e o mal sem o saber; e nossas ações não pos- suem significado moral, embora haja por vezes no sentimento das ações de outrem em relação a nós. (OC iv 288) (1992, p. 48; 2004, S. 166)

Da razão, brota o conhecimento da moralidade, da consciência, o seu sentimento ${ }^{5}$. Assim, a moralidade das ações humanas é pensada a partir do confronto entre razão e consciência, entre sentir e conhecer: ao tratar da relação entre consciência e razão, mesmo que de forma assistemática, Rousseau vincula a consciência diretamente à nossa sensibilidade e a concebe como sendo anterior tanto à razão como à moralidade. Ela é um espaço aquém da razão, do qual esta, mesmo diferenciando-se da consciência, não deixaria de ser seu desdobramento. É a dupla dimensão da consciência, como ‘instinto divino’ e como origem da racionalidade moral, que torna seu 'ato obscuro', revelando com isso toda sua ambigüidade: por um lado, como 'instinto divino', contém uma dimensão impulsiva que a impede de agir segundo a representação de leis e, portanto, segundo máximas a priori; por outro, quando confrontado com aquele seu prolongamento, isto é, com a razão, passa a pertencer ao 'plano superior' da natureza, misturando-se com a dimensão livre e racional do ser humano (Guéroult, 1972). Podemos nos perguntar a esta altura, se aqui se trata realmente de uma obscuridade ou se Rousseau não está tocando num dos problemas mais profundos e controversos da filosofia prática, o qual Kant formulou, poucos anos mais tarde, também enigmaticamente, com a expressão "Stein der Weisen"? ${ }^{6}$

Visto do ponto de vista antropológico, poder-se-ia dizer que a consciência seria a sede do amour de soi-même que, ao manter-se aquém da razão, sem confrontar-se com ela, permaneceria moralmente neutra. No entanto, por meio do processo de socialização, confron-

5. Sob esse aspecto, segundo a interpretação de Lévi-Strauss (1972), a piedade pode ser concebida como uma força intermediária que, por ter sua raiz tanto na consciência como na razão, pode ser tanto afetiva como racional, animal como humana e, enfim, podendo significar tanto natureza como cultura. 6. Sobre isso, ver Dalbosco (2003). 
tando-se com o sentimento do amour-propre, seu princípio inato de justiça e de virtude adquiriria um conteúdo moral propriamente dito. A moralidade resultaria então da tensão entre 0 princípio de justiça e virtude que reside na consciência e seu inevitável confronto com capacidade humana reflexiva oriunda do processo de socialização humana. Se tal interpretação procede, como ela fica evidente que o simples apelo à voz interna da consciência ou somente o recurso de conhecimento que brota da razão não são suficientes, isoladamente, para a formação moral do Emílio, também não sendo suficientes, portanto, para constituírem a moralidade das ações humanas. Por isso, nesse contexto, ouvir a voz da consciência nada mais significa do que a exigência de confrontála com a capacidade racional de julgamento e, visto pelo lado da razão, as ações humanas também precisam ser constantemente confrontadas à voz do coração. Se o contexto argumentativo rousseauniano não esclarece a 'obscuridade do ato da consciência', parece deixar claro, ao menos, sua dupla dimensão, a sensível e a racional, fazendo de ambas a sede da moralidade das ações humanas.

\section{Algumas implicações pedagógicas}

A crítica à sociedade feita por Rousseau significa, ao mesmo tempo, uma crítica à origem social da maldade e, num sentido mais amplo, da própria moralidade humana. Tal crítica está também na base de seu projeto educacional: Emílio, seu educando imaginário, deve ser ensinado a suportar todo tipo de "mal físico'. Rousseau considera a capacidade de suportar privações e necessidades como um princípio pedagógico genuíno para servir como ponto de partida, mas não como ponto de chegada da educação, da vontade contra seu próprio livre arbítrio, isto é, contra uma 'liberdade desregrada' de uma vontade que pensa que o simples querer já é poder tudo. No entanto, quando se trata do 'mal social', Emílio deve ser ensinado a não suportá-lo com a mesma intensidade em que é preparado a suportar as intempéries naturais. Do ponto de vista antropológico, o sentimento egoísta do amo-próprio deve ser, portanto, confrontado reflexivamente com a piedade e com o sentimento de humanidade emergentes do amor de si mesmo. A origem do mal social deve-se, nesse caso, ao esforço concentrado do sentimento egoísta do amor-próprio em preservar seus interesses privados à custa dos outros, sufocando a perspectiva universalizante de poder incluir a humanidade e, portanto, o outro em sua ação. Isso aponta para uma tese central da teoria educacional exposta no Émile: a educação do Emílio só faz sentido quando pensada dentro e não fora da sociedade e a questão decisiva que se coloca para seu projeto é o de que Emílio deve formar-se socialmente, apreendendo a viver bem consigo mesmo e com os demais, para poder construir relações moralmente autônomas no interior da sociedade da qual faz parte. Esse é um dos motivos que torna a educação moral uma referência indispensável à formação da identidade do ser humano a tal ponto que este seja capaz de viver bem consigo mesmo e com os outros.

De outra parte, estando em estreita sintonia com as teorias social e antropológica, o esboço da teoria da determinação racional da vontade também deve oferecer argumentos para o confronto, por meio de um trabalho educativo da tendência egoísta do amor-próprio, com o processo de estranhamento oriundo da sociabilidade humana, visando à recuperação do sentimento do amor de si mesmo no convívio social. Dentro desse contexto, o projeto educacional de Emílio não consiste em negar o estado social, como se fosse possível educá-lo fora da sociedade, mas dito em termos antropológicos, tornar visível, dentro de tal estado, a tensão entre os dois tipos de sentimentos constitutivos da personalidade humana, o amor de si mesmo e o amor-próprio.

Expressado em termos jurídicos e políticos, Rousseau imagina, contrafaticamente, na 
educação de Emílio, um desenvolvimento em direção a uma comunidade genuinamente humana, que não mais necessitaria das molas do poder nos moldes de uma subjetividade egoísta do amor-próprio, centrada unicamente em si mesma, mas enraizada na sujeição comum à lei, interiormente reconhecida como obrigatória e necessária. Nesse sentido, sua teoria educacional precisa estar amparada por uma teoria da obrigação moral que mostre ao Emílio, progressivamente, a importância da sujeição à lei como uma condição indispensável à conquista de sua consciência cidadã. 0 processo pedagógico deve se constituir num processo de interiorização crítica da lei no sentido de que Emílio sinta-se, no decorrer de seu processo educativo, obrigado racional e livremente a respeitá-la.

Visto em termos educativos, o ideal de Rousseau exige a substituição progressiva da ação coercitiva e disciplinatória, próprias ao período educacional da infância e tematizado exaustivamente nos três primeiros livros do Émile, pela ação moral obrigatória, própria ao período da vida humana que se caracteriza pelo uso da razão, isto é, ao período que começa com a juventude e que é tematizado nos livros IV e V do Émile ${ }^{7}$. De outra parte, seu ideal normativo societário exige, por sua vez, a substituição da ação coercitiva social pela ação humana livre de uma comunidade política e ética, na qual cada um só obedece a vontade geral, em vez de se submeter às vontades individuais centradas no amor-próprio egoísta. Disso se pode concluir que toda a teoria educacional que permanecer somente na primeira etapa, isto é, que pense um processo pedagógico baseado só na ação coercitiva e disciplinadora da criança, sem visualizar a ação moralmente obrigada, orientada por máximas, princípios e leis, pode formar seres humanos adestrados, mas jamais cidadãos. Essa é mais uma prova de que o projeto rousseauniano de uma educação natural deve estar sustentado tanto por uma teoria moral como jurídico-política.
0 problema que permanece em aberto aqui, considerando a imbricação de argumentos provindos tanto da teoria social como antropológica e educacional, é o de saber até que ponto o sentimento de obrigação moral perante a lei é suficiente para fazer frente ao mal social anteriormente diagnosticado? Pode-se formular momentaneamente a idéia de que, enquanto a teoria moral, baseada na determinação racional da vontade, deveria pensar os fundamentos para que uma consciência se sentisse obrigada racionalmente a respeitar a lei, a teoria jurídica deveria oferecer o ordenamento legal que assegurasse objetivamente, baseando-se inclusive em procedimentos coercitivos, aquela obrigação. No entanto, é evidente que o argumento de Rousseau não aponta sistematicamente para essa direção e uma das razões deve-se ao fato de ele tratar dessa problemática num contexto histórico, início da modernidade, no qual as relações humano-sociais não se encontram ainda plenamente juridificadas ${ }^{8}$. Ou seja, ele pensa a relação entre moralidade e direito nos termos de que o nível de obrigação derivado da moralidade já seria força motivadora suficiente para a execução da ação nos termos exigidos pela própria obrigação moral. Seu conceito de sociedade atribui, nesse sentido, maior peso à moralidade, exigindo menos interferência do poder coercitivo das ações jurídicas.

\footnotetext{
7. A pedagogia kantiana pode ser interpretada em termos muito semelhantes, uma vez que Kant exige, em seu projeto educacional, a passagem da ação disciplinada à obrigação moral. Sobre isso, ver Dalbosco (2004a; 2004b). 8. Emprego o termo 'juridificação' no sentido que Flickinger (2004) Ihe atribui, considerando, no entanto, o contexto completamente diferenciado que marca nossas abordagens. Juridificação significa, segundo ele, "o fato de a sociedade liberal moderna orgulhar-se da transformação abrangente das relações sociais e institucionais em relações juridicamente determinadas, a fim de garantir o reconhecimento da liberdade de todos os seus membros. De fato, o status de membro da sociedade define-se aí pela qualificação do indivíduo como 'pessoa de direito', ou seja, por sua determinação jurídica" (p. 98).
} 


\section{Referências bibliográficas}

CASSIRER, E. A questão de Jean-Jacques Rousseau. In: QUIRINO, C. G.; SOUZA, M. T. S. R. 0 pensamento político clássico. São Paulo: T. A. Queiroz, 1980, p. 379-418.

DALBOSCO, C. A. Racionalidade prática e práxis pedagógica: considerações introdutórias. In: pedagogia. Passo Fundo: UPF Editora, 2003, p. 13-29. (Org.). Filosofia prática e

A. "Vom disziplinierten Zwang zur moralischen Verbindlichkeit. Zur Bedeutung und Rolle der Pädagogik bei Kant". Pädagogische Rundschau, n. 58, 2004a, p. 385-400.

Da pressão disciplinada à obrigação moral: esboço sobre o significado e o papel da pedagogia no pensamento de Kant. Educação \& Sociedade, v. 25, n. 89, 2004b, p. 1333-1356.

. Teoria social, antropologia filosófica e educação natural em Rousseau. In: DALBOSCO, C. A.; FLICKINGER, H. G. Educação e maioridade: dimensões da racionalidade pedagógica. Passo Fundo: UPF Editora; São Paulo: Cortez, 2005, p. 70-103.

FLICKINGER, H. G. A juridificação da liberdade: os direitos humanos no processo de Globalização. Revistas de Estudos Criminais, ano IV, n. 16, 2004, p. 97-106

GUÉROULT, M. Naturaleza humana y estado de naturaleza en Rousseau, Kant y Fichte. In: LÉVI-STRAUSS et al. Presencia de Rousseau. Buenos Aires: Ediciones Visión, 1972, p. 141-162.

KERSTING, W. Die politische Philosophie des Gesellschaftsvertrags. Darmstadt: WB, 1994.

KOCH, L. Wohlgeregelte Freiheit. Rousseaus Bildungsprinzip. In: HANSMANN, O. (Hrsg.). Seminar: der pädagogische Rousseau. Band II: Kommentare, Interpretationen, Wirkungsgeschichte. Weinheim: Deutscher Studien Verlag, 1996, p. 141-166.

LÉVI-STRAUSS, C. Jean-Jacques Rousseau, fundador de las ciencias del hombre. In: LÉVI-STRAUSS et al. Presencia de Rousseau. Buenos Aires: Ediciones Visión, 1972. p. 07-19.

ROUSSEAU, J. J. Oeuvres complètes. Paris: Gallimard, Bibliothèque de la Plêiade, 5 v., 1959-1995.

Du contrat social: ecrits politiques. vol. III. Paris: Gallimard, Bibliothèque de la Pléiade, 1964.

Émile: education - morale - botanique. v. IV. Paris: Gallimard, Bibliothèque de la Pléiade, 1969.

Gesellschaftsvertrag. Stuttgart: Reclam, 2003a.

Emil oder Über die Erziehung. Stuttgart: Reclam, 2004.

Emilio ou da Educação. Rio de Janeiro: Bertrand Brasil, 1992.

Do contrato social: ensaio sobre a origem das línguas; discurso sobre a origem e os fundamentos da desigualdade entre os homens; discurso sobre as ciências e as artes. São Paulo: Abril Cultural, 1978. (Coleção os Pensadores).

SCHÄFER, A. Jean-Jacques Rousseau: ein pädagogisches porträt. Weinheim und Basel: Beltz Verlag, 2002.

TAYLOR, C. Quellen des selbst: die entstehung der neuzeitlichen identität. Frankfurt am Main: Suhrkamp, 1996.

Recebido em 26.01.06

Aprovado em 07.08.06

Cláudio Almir Dalbosco é doutor pela Universität Kassel (Alemanha) e professor do curso de Filosofia e do Programa de Pós-graduação em Educação da Universidade de Passo Fundo. 